\title{
Kinematics of gait using bionic and hydraulic knee joints in transfemoral amputees
}

\author{
Jaroslav Uchytil ${ }^{1, *}$, Daniel Jandačka ${ }^{1}$, Roman Farana ${ }^{1}$, David Zahradník ${ }^{1}$, Jiri Rosicky², \\ and Miroslav Janura ${ }^{3}$
}

${ }^{1}$ Faculty of Education, University of Ostrava, Ostrava, Czech Republic; ${ }^{2} I N G$ Corporation, spol. s r. o., Frýdek-Místek, Czech Republic; and ${ }^{3}$ Faculty of Physical Culture, Palacký University Olomouc, Olomouc, Czech Republic

Copyright: (C) 2017 J. Uchytil et al. This is an open access article licensed under the Creative Commons Attribution License (http://creativecommons.org/licenses/by/4.0/).

\begin{abstract}
Background: The development of new technologies has led to further improvements in prosthetic knee joints. Objective: The aim of this study was to compare angle parameters in knee and hip joints during the gait of transfemoral amputees and to determine the effect of the type of knee joint used on their symmetry. The study also compared pelvic movements in transfemoral amputees using different types of knee joints. Method: Eleven patients ( 5 female, 6 male, mean age $39.2 \pm 10.1$ years, height $171.8 \pm 9.5 \mathrm{~cm}$, mass $71.5 \pm 11.0 \mathrm{~kg}$ ) with a transfemoral amputation ( 5 used bionic knee, 6 used hydraulic knee) participated in this study. The control group consisted of 10 individuals with no locomotion-related problems ( 2 female, 8 male). Results: Movement was more symmetrical in the hip joint for all monitored parameters in patients with bionic knee joints. Flexion at heel contact and maximum flexion in the swing phase in the knee joint were more symmetrical in the group with hydraulic knee joints; for all other parameters the group with bionic knee joints achieved better symmetry. The kinematics of pelvic movement in the patients using hydraulic knee joints differed from the control group in all monitored parameters. The greatest difference with excellent effect size (ES = 7.96) was found in pelvic tilt. Pelvic tilt was higher when using hydraulic knee joints. Conclusion: In comparison with the mechanically passive knee joint, gait with the bionic knee joint evinced gait symmetry.
\end{abstract}

Keywords: amputation, prosthesis, bionic knee joint, kinematic analysis

\section{Introduction}

Approximately 200 to 500/million major amputations are perfomed globally every year (Dormandy, Heeck, \& Vig, 1999), of which $85 \%$ are performed on lower limbs (Kishner, 2013). In view of this fact, it is important to channel increased effort into developing prosthetic technology, without which patients are usually unable to walk. This is also the case with transfemoral prostheses including prosthetic knee joints. The function of the prosthetic knee joint has a significant impact on the patient's ability to walk after the amputation. A prosthetic knee joint has to "simulate" the movement of a human knee, provide stability in weight transfer during the stance phase, and allow the control of limb movement during the swing phase (Silver-Thorn \& Glaister, 2009).

\footnotetext{
* Address for correspondence: Jaroslav Uchytil, Department of Human Movement Studies, Faculty of Education, University of Ostrava, Varenská 40a, 70103 Ostrava, Czech Republic. E-mail: jaroslav.uchytil@osu.cz
}

The development of new technologies has led to further improvements in prosthetic knee joints. Many modern types of prosthetic knee joints use microprocessors to control the stance and swing phases, enabling amputees to walk with greater comfort. In cases of pathological gait there may be a pronounced difference between the two sides, leading to arrhythmic gait patterns - which may in turn have a negative impact on the musculoskeletal apparatus (Bartlett, Wheat, \& Robins, 2007). One of the goals when developing prostheses and setting up their components is to reduce gait asymmetry between the intact limb and the affected limb. In cases when only one limb is amputated, symmetrical gait can prevent the excessive loading of the intact limb (Nolan et al., 2003). Quantifying gait asymmetry in amputees compared to non-amputees is the first step in the process of defining what degree of asymmetry is acceptable when walking with the prosthesis during the rehabilitation process (Dingwell, Davis, \& Frazier, 1996).

A frequent secondary problem in lower limb amputees is back pain (Hemakumar, Tumilty, \& Smith, 2012). Biomechanical factors play a major role contributing to 
back pain in lower limb amputees (Morgenroth, Shakir, Orendurff, \& Czerniecki, 2009). Cappozzo, Figura, Gazzani, Leo, and Marchetti (1982) described differences in pelvic movements during the stance phase in transfemoral amputees compared with non-amputees. Developing a gait pattern similar to non-amputees may help reduce back pain in transfemoral amputees. Adequate prosthetic equipment can play a key role in this process.

Several studies compared kinematics of gait among transfemoral amputees wearing different types of prosthetic knee joint (Bellmann, Schmalz, \& Blumentritt, 2010; Johansson, Sherrill, Riley, Bonato, \& Herr, 2005; Kaufman, Frittoli, \& Frigo, 2012; Mâaref et al., 2010; Segal et al., 2006). However, in some studies subjects moved at their own natural speed, which was different in many cases, and in other studies subjects had a short time to become accustomed to the new type of prosthetic knee design (Johansson et al., 2005; Kaufman et al., 2012; Mâaref et al., 2010). In our study all subjects walked at identical range of speed to reduce the effect of potentially confounding variables (Nolan et al., 2003; Schaarschmidt, Lipfert, Meier-Gratz, Scholle, \& Seyfarth, 2012; Stoquart, Detrembleur, \& Lejeune, 2008 ) and all patients had been using a prosthetic knee joint for two or more years. The aim of this study was to compare angle parameters in knee and hip joints for both intact and affected limbs during the gait of transfemoral amputees and to determine the effect of the type of knee joint used (bionic, hydraulic) on their symmetry. The study also compared pelvic movements in transfemoral amputees using different types of knee joint in relation to non-pathological gait. We hypothesize that patients who use bionic knee prosthetic joints have greater symmetry and their kinematics of gait is more similar to the gait pattern of the control group.

\section{Methods}

\section{Participants}

The experiment involved 11 participants ( 5 female, 6 male) who had undergone transfemoral amputations (mean age $39.2 \pm 10.1$ years, height $171.8 \pm 9.5 \mathrm{~cm}$, mass $71.5 \pm 11.0 \mathrm{~kg}$ ). Seven of the patients had an amputation of the right lower limb, and four had amputation of the left lower limb. The cause of amputation was oncological for seven patients and traumatic of three patients. Five participants ( 3 female, 2 male, mean age $37.1 \pm 8.1$ years, height $170.2 \pm 8.3 \mathrm{~cm}$, mass $71.6 \pm 10.2 \mathrm{~kg}$ ) used a Rheo bionic knee joint (Össur, Reykjavik, Iceland), while six ( 2 female, 4 male, mean age $38.6 \pm 9.1$ years, height $171.9 \pm 10.5 \mathrm{~cm}$, mass $73.2 \pm 10.3 \mathrm{~kg}$ ) used a non-controlled knee joint based on hydraulic principles. The patients using the hydraulic joint had been identified as potential users of bionic joints. All other prosthetic equipment was of a similar type (SACH foot and ischial containment socket). All the participants had used their prosthetic knee joint for a period of more than two years (bionic knee $2.8 \pm 0.8$ years, hydraulic knee $3.2 \pm 1.6$ years). The control group consisted of 10 individuals with no locomotion-related problems ( 8 male and 2 female, age $27.6 \pm 5.2$ years, height $175.2 \pm 6.8 \mathrm{~cm}$, mass $70.1 \pm 6.1 \mathrm{~kg}$ ). The control group was selected from 50 analyzed persons so that their natural gait speed would correspond with the gait speed of the transfemoral amputees. The study was approved by the Ethics and Research Committee of the Human Motion Diagnostic Center, Faculty of Education, University of Ostrava. All subjects provided written informed consent.

\section{Protocol}

Each of the participants visited the biomechanics laboratory on two different days. On each visit the participants received instructions and then performed 15 valid trials walking along a 16 meter-long track, which were analyzed. The participants performed 2-5 preparatory attempts before each measurement. Their movement was recorded using eight infra-red cameras. Only those trials in which the gait speed ranged between 1.09 and $1.21 \mathrm{~m} / \mathrm{s}$ were considered as valid. This speed was set on the basis of the determined gait speed of persons using transfemoral prostheses (Johansson et al., 2005). Calibration markers for determining kinematic parameters were positioned bilaterally on the lateral and medial malleolus, the lateral and medial femoral condyles, the greater trochanter of the femur, and the first and fifth metatarsal heads. Tracking markers were positioned to define the trunk (acromion), pelvis (iliac crest, posterior superior iliac spine, anterior superior iliac spine), thigh and shank (a cluster of four lightweight rigid plates on which were positioned four markers), and foot (three markers - posterior calcaneus, lateral calcaneus, proximal calcaneus). Before the trials, a standing calibration trial of the participants was carried out.

\section{Measurements}

A set of eight Qualisys Oqus 100 infra-red cameras was used for the kinematic analysis (Qualisys AB, Göteborg, Sweden); the cameras were connected to an A/D converter and a compatible computer. The frequency of the cameras was $247 \mathrm{~Hz}$. Gait speed was monitored using EGMEDICAL OPZZ15 wireless photocells (EGMedical, s. r. o., Brno, Czech Republic), located at intervals of $3 \mathrm{~m}$ along the track. 


\section{Data analysis}

The raw data were processed using Qualysis Track Manager software (QTM, Qualisys AB, Göteborg, Sweden). The modelling and data processing were performed using Visual3D v4 software (C-motion, Rockville, MD, USA). The individual segments of the lower limb were modelled as truncated cones. The local coordination system of the thighs, shanks and feet was derived from the standing calibration trial. The symmetry between the affected and intact limbs was also evaluated. The control group values were taken as the mean of the left and right lower limbs.

The monitored values in the hip joint were: $\mathrm{H}_{\mathrm{FHC}}$ - flexion at heel contact, $\mathrm{H}_{\mathrm{E}}$ - maximum extension in stance phase, $\mathrm{H}_{\mathrm{F}}$ - maximum flexion in swing phase, $\mathrm{H}_{\mathrm{AD}}$ - maximum adduction in stance phase, $\mathrm{H}_{\mathrm{AB}}$ - maximum abduction in swing phase, $\mathrm{H}_{\mathrm{IR}}$ - maximum internal rotation in stance phase, $\mathrm{H}_{\mathrm{ER}}$ - maximum external rotation in swing phase. The monitored values in the knee joint were: $\mathrm{K}_{\mathrm{FHC}}$ - flexion at heel contact, $\mathrm{K}_{\mathrm{FLR}}$ - maximum flexion during loading response, $\mathrm{K}_{\mathrm{E}}$ - maximum extension in stance phase, $\mathrm{K}_{\mathrm{FS}}$ - maximum flexion in swing phase, $\mathrm{K}_{\mathrm{IR}}$ - maximum internal rotation in stance phase, $\mathrm{K}_{\mathrm{ER}}$ - maximum external rotation in swing phase. The monitored values for pelvic movement were: $\mathrm{P}_{T}-$ minimum pelvic tilt in sagittal plane, $\mathrm{P}_{\text {OMIN }}$ - minimum pelvic obliquity in frontal plane, $\mathrm{P}_{\text {OMAX }}$ - maximum pelvic obliquity in frontal plane, $P_{R}-$ maximum rotation in transverse plane. These selected values are among the most frequently used for gait analysis in clinical practice (Benedetti, Catani, Leardini, Pignotti, \& Giannini, 1998).

\section{Statistical analysis}

Statistical analyses were performed using IBM SPSS Statistics (Version 23; IBM, Armonk, NY, USA). Reliability was verified using the intraclass correlation coefficient (ICC). The mean relative typical measurement error was calculated in percentage terms (Hopkins, 2000) for intact and affected limbs. To compare the data of the control and prosthetic groups, the MannWhitney $U$ test was used. The significance level was set at $p<.05$.

Gait symmetry was evaluated via the symmetry index (SI) from the equation:

$\mathrm{SI}=\left(\left[\mathrm{X}_{\text {intact }}-\mathrm{X}_{\text {affected }}\right] / 0.5\left[\mathrm{X}_{\text {intact }}+\mathrm{X}_{\text {affected }}\right]\right) \cdot 100 \%$ for prosthetic group, and:

$\mathrm{SI}=\left(\left[\mathrm{X}_{\text {Right }}-\mathrm{X}_{\text {Left }}\right] / 0.5\left[\mathrm{X}_{\text {Right }}+\mathrm{X}_{\text {Left }}\right]\right) \cdot 100 \%$ for control group.

The values for SI can range from $-100 \%$ to $+100 \%$; zero represents absolute symmetry (Dingwell et al., 1996). Effect size (ES) was used to express the practical significance of differences. The values of ES (Cohen's $d$ ) are expressed as follows: $0-0.2=$ negligible effect; 0.2-0.6 = small effect; 0.6-1.2 = medium effect; 1.2-2.0 = large effect; $2.0-4.0=$ very large effect, 4.0 and upwards = excellent effect (Hopkins, 2014).

\section{Results}

ICC value was higher than 0.8 and the relative typical measurement error was lower than $5 \%$ in all observed variables.

\section{Hip joints}

Patients with bionic knee joints achieved significantly greater maximum extension angles than the control group in the stance phase $\left(\mathrm{H}_{\mathrm{E}}\right)$ on intact limbs $(\mathrm{ES}=2.49 ; p=.03)$ and practically significantly greater on affected limbs $(\mathrm{ES}=1.21 ; p=.04)$.

At heel contact $\left(\mathrm{H}_{\mathrm{FHC}}\right)$, patients with hydraulic knee joints achieved significantly lower angles than the control group on intact limbs $(\mathrm{ES}=1.21 ; p=.04)$ and significantly greater angles than the control group on affected limbs $(\mathrm{ES}=2.12 ; p=.03)$. There is a difference with excellent effect $(\mathrm{ES}=5.09 ; p=.01)$ in comparison with the control group for the maximum extension in the stance phase $\left(\mathrm{H}_{\mathrm{E}}\right)$ on intact limbs. Significant differences with large effect between the control group and patients with hydraulic knee joints exist for maximum flexion $\left(\mathrm{H}_{\mathrm{F}}\right)$ on affected limbs during the swing phase $(\mathrm{ES}=1.48 ; p=.04)$ and for maximum external rotation $\left(\mathrm{H}_{\mathrm{ER}}\right)$ in the swing phase on intact limbs $(\mathrm{ES}=1.81 ; p=.04)$ (Table 1$)$.

Symmetry of lower limb movement in the hip joint is greater for all monitored parameters in patients with bionic knee joints in comparison with hydraulic knee joint. The greatest asymmetry in hydraulic knee joint patients was found in the maximum extension in the stance phase $\left(\mathrm{H}_{\mathrm{E}}\right)$, the maximum adduction in the stance phase $\left(\mathrm{H}_{\mathrm{AD}}\right)$, and the maximum external rotation $\left(\mathrm{H}_{\mathrm{ER}}\right)$ in the swing phase (Table 2).

\section{Knee joints}

In comparison with the control group, both groups of amputees achieved lower maximum flexion during the loading response on the affected limb $\left(\mathrm{K}_{\mathrm{FLR}}\right)$. There is a difference with excellent effect ( $E S=4.52$; $p=.01$ ) for the maximum flexion in the swing phase $\left(\mathrm{K}_{\mathrm{FS}}\right)$ on affected limbs among the patients with bionic knee joints. There is also a difference with large effect ( $\mathrm{ES}=1.32 ; p=.04)$ for this parameter among the patients with hydraulic knee joints, but on the intact limb (Table 3). 
Table 1

Comparison of angle parameters in the hip joint during gait of patients with bionic knee joints (Rheo), patients with hydraulic knee joints (Hydraulic) and the control group (Control)

\begin{tabular}{|c|c|c|c|c|c|}
\hline Variable/Limb & Rheo & Hydraulic & Control & ES/sig. Rheo & ES/sig. Hydraulic \\
\hline \multicolumn{6}{|l|}{$\mathrm{H}_{\mathrm{FHC}}\left({ }^{\circ}\right)$} \\
\hline Intact & $-26.49 \pm 4.62$ & $-22.18 \pm 6.36$ & $-27.14 \pm 4.10$ & 0.16 & $1.21 /^{*}$ \\
\hline Affected & $-29.93 \pm 4.45$ & $-35.82 \pm 6.18$ & & 0.68 & $2.12 /^{*}$ \\
\hline \multicolumn{6}{|l|}{$\mathrm{H}_{\mathrm{E}}\left({ }^{\circ}\right)$} \\
\hline Intact & $16.39 \pm 5.67$ & $24.53 \pm 4.08$ & $8.56 \pm 3.14$ & $2.49 / *$ & $5.09 / *$ \\
\hline Affected & $12.39 \pm 3.31$ & $9.63 \pm 7.94$ & & 1.21 & 0.34 \\
\hline \multicolumn{6}{|l|}{$\mathrm{H}_{\mathrm{F}}\left({ }^{\circ}\right)$} \\
\hline Intact & $-31.67 \pm 5.72$ & $-30.25 \pm 5.53$ & $-28.74 \pm 5.10$ & 0.57 & 0.30 \\
\hline Affected & $-31.95 \pm 3.74$ & $-36.30 \pm 6.48$ & & 0.63 & $1.48 /^{*}$ \\
\hline \multicolumn{6}{|l|}{$\mathrm{H}_{\mathrm{AD}}\left({ }^{\circ}\right)$} \\
\hline Intact & $-6.43 \pm 4.54$ & $-4.15 \pm 6.37$ & $-9.43 \pm 4.66$ & 0.64 & 1.13 \\
\hline Affected & $-7.59 \pm 5.15$ & $-10.72 \pm 4.75$ & & 0.39 & 0.28 \\
\hline \multicolumn{6}{|l|}{$\mathrm{H}_{\mathrm{AB}}\left({ }^{\circ}\right)$} \\
\hline Intact & $5.74 \pm 2.70$ & $2.84 \pm 5.37$ & $6.62 \pm 5.46$ & 0.16 & 0.69 \\
\hline Affected & $6.86 \pm 3.35$ & $3.78 \pm 3.62$ & & 0.04 & 0.50 \\
\hline \multicolumn{6}{|l|}{$\mathrm{H}_{\mathrm{IR}}\left({ }^{\circ}\right)$} \\
\hline Intact & $4.49 \pm 3.43$ & $2.64 \pm 8.60$ & $5.76 \pm 3.28$ & 0.39 & 0.95 \\
\hline Affected & $6.04 \pm 3.57$ & $4.12 \pm 7.26$ & & 0.09 & 0.5 \\
\hline \multicolumn{6}{|l|}{$\mathrm{H}_{\mathrm{ER}}\left({ }^{\circ}\right)$} \\
\hline Intact & $-3.02 \pm 1.77$ & $-3.11 \pm 3.51$ & $-7.89 \pm 2.64$ & $1.84 / *$ & $1.81 /^{*}$ \\
\hline Affected & $-7.58 \pm 5.49$ & $-10.86 \pm 6.31$ & & 0.12 & 1.13 \\
\hline
\end{tabular}

Note. $\quad$ ES Rheo = difference between the bionic joint group and the control group; ES Hydraulic = difference between the hydraulic joint group and the control group. $\mathrm{H}_{\mathrm{FHC}}$ = flexion at heel contact; $\mathrm{H}_{\mathrm{E}}=$ maximum extension in stance phase; $\mathrm{H}_{\mathrm{F}}=$ maximum flexion in swing phase; $\mathrm{H}_{\mathrm{AD}}$ = maximum adduction in stance phase; $\mathrm{H}_{\mathrm{AB}}$ = maximum abduction in swing phase; $\mathrm{H}_{\mathrm{IR}}=$ maximum internal rotation in stance phase; $\mathrm{H}_{\mathrm{ER}}=$ maximum external rotation in swing phase. $\quad{ }^{*} p<.05$.

Table 2

Symmetry indexes for hip joint angles for bionic knee joints (SI Rheo), hydraulic knee joints (SI Hydraulic) and the control group (SI Control)

\begin{tabular}{lccccc}
\hline Variable & SI Rheo (\%) & SI Hydraulic (\%) & SI Control (\%) & ES/sig. Rheo & ES/sig. Hydraulic \\
\hline $\mathrm{H}_{\mathrm{FHC}}$ & $6.05 \pm 4.60$ & $22.38 \pm 6.26$ & $2.85 \pm 1.05$ & 0.96 & $4.35 / *$ \\
$\mathrm{H}_{\mathrm{E}}$ & $12.34 \pm 5.25$ & $51.72 \pm 7.26$ & $3.12 \pm 1.28$ & 2.41 & $7.67 / *$ \\
$\mathrm{H}_{\mathrm{F}}$ & $0.44 \pm 2.25$ & $6.99 \pm 4.05$ & $1.03 \pm 0.55$ & 0.36 & $2.06 / *$ \\
$\mathrm{H}_{\mathrm{AD}}$ & $8.22 \pm 3.12$ & $46.12 \pm 9.87$ & $2.17 \pm 0.85$ & 2.65 & $6.27 / *$ \\
$\mathrm{H}_{\mathrm{AB}}$ & $8.31 \pm 2.91$ & $9.82 \pm 5.22$ & $1.98 \pm 0.86$ & $2.95 / *$ & $2.10 / *$ \\
$\mathrm{H}_{\mathrm{IR}}$ & $13.46 \pm 3.73$ & $22.83 \pm 6.64$ & $2.26 \pm 1.06$ & $4.08 / *$ & $4.32 /^{*}$ \\
$\mathrm{H}_{\mathrm{ER}}$ & $24.81 \pm 5.18$ & $37.36 \pm 5.58$ & $3.18 \pm 1.15$ & $5.76 / *$ & $8.48 / *$ \\
\hline
\end{tabular}

Note. ES Rheo = difference between the bionic joint group and the control group; ES Hydraulic = difference between the hydraulic joint group and the control group. $\mathrm{H}_{\mathrm{FHC}}=$ flexion at heel contact; $\mathrm{H}_{\mathrm{E}}=$ maximum extension in stance phase; $\mathrm{H}_{\mathrm{F}}=$ maximum flexion in swing phase; $\mathrm{H}_{\mathrm{AD}}=$ maximum adduction in stance phase; $\mathrm{H}_{\mathrm{AB}}=$ maximum abduction in swing phase; $\mathrm{H}_{\mathrm{IR}}=$ maximum internal rotation in stance phase; $\mathrm{H}_{\mathrm{ER}}=$ maximum external rotation in swing phase. $\quad{ }^{*} p<.05$. 
Flexion at heel contact $\left(\mathrm{K}_{\mathrm{FHC}}\right)$ and maximum flexion in the swing phase $\left(\mathrm{K}_{\mathrm{FS}}\right)$ were more symmetrical in the group with hydraulic knee joints; for all other parameters the group with bionic knee joints achieved better symmetry. The greatest asymmetry in both groups of amputees is for flexion during the loading response $\left(\mathrm{K}_{\mathrm{FLR}}\right)$ (Table 4$)$.
Pelvis

The kinematics of pelvic movement in the patients using hydraulic knee joints differ from the control group in all monitored parameters. The greatest difference with excellent effect $(\mathrm{ES}=7.96 ; p<.01)$ is in pelvic tilt on the side of the intact limb. In this parameter the control group also differs with very large effect

Table 3

Comparison of angle parameters in the knee joint during gait of patients with bionic knee joints (Rheo), patients with hydraulic knee joints (Hydraulic) and the control group (Control)

\begin{tabular}{|c|c|c|c|c|c|}
\hline Variable/Limb & Rheo & Hydraulic & Control & ES/sig. Rheo & ES/sig. Hydraulic \\
\hline \multicolumn{6}{|l|}{$\mathrm{K}_{\mathrm{FHC}}\left({ }^{\circ}\right)$} \\
\hline Intact & $1.05 \pm 2.71$ & $3.61 \pm 3.46$ & $1.54 \pm 3.40$ & 0.14 & 0.61 \\
\hline Affected & $0.15 \pm 1.47$ & $3.74 \pm 6.68$ & & 0.41 & 0.65 \\
\hline \multicolumn{6}{|l|}{$\mathrm{K}_{\mathrm{FLR}}\left({ }^{\circ}\right)$} \\
\hline Intact & $20.06 \pm 5.30$ & $20.03 \pm 5.33$ & $17.60 \pm 4.21$ & 0.58 & 0.58 \\
\hline Affected & $2.89 \pm 1.77$ & $1.96 \pm 1.31$ & & $3.49 / *$ & $3.71 / *$ \\
\hline \multicolumn{6}{|l|}{$\mathrm{K}_{\mathrm{E}}\left({ }^{\circ}\right)$} \\
\hline Intact & $4.65 \pm 3.16$ & $4.61 \pm 5.23$ & $4.77 \pm 3.77$ & 0.03 & 0.04 \\
\hline Affected & $3.93 \pm 1.62$ & $1.67 \pm 2.32$ & & 0.22 & 0.82 \\
\hline \multicolumn{6}{|l|}{$\mathrm{K}_{\mathrm{FS}}\left({ }^{\circ}\right)$} \\
\hline Intact & $66.14 \pm 5.05$ & $60.14 \pm 2.00$ & $64.96 \pm 3.64$ & 0.32 & $1.32 / *$ \\
\hline Affected & $48.52 \pm 8.17$ & $61.28 \pm 9.80$ & & $4.52 / *$ & 1.01 \\
\hline \multicolumn{6}{|l|}{$\mathrm{K}_{\mathrm{IR}}\left({ }^{\circ}\right)$} \\
\hline Intact & $8.28 \pm 3.02$ & $10.84 \pm 5.98$ & $5.64 \pm 3.71$ & 0.71 & $1.40 / *$ \\
\hline Affected & $5.97 \pm 2.64$ & $7.45 \pm 5.59$ & & 0.09 & 0.49 \\
\hline \multicolumn{6}{|l|}{$\mathrm{K}_{\mathrm{ER}}\left({ }^{\circ}\right)$} \\
\hline Intact & $9.23 \pm 3.22$ & $11.65 \pm 5.49$ & $9.13 \pm 4.80$ & 0.02 & 0.53 \\
\hline Affected & $8.77 \pm 3.51$ & $8.73 \pm 6.55$ & & 0.08 & 0.08 \\
\hline
\end{tabular}

Note. ES Rheo = difference between the bionic joint group and the control group; ES Hydraulic = difference between the hydraulic joint group and the control group. $\mathrm{K}_{\mathrm{FHC}}=$ flexion at heel contact, $\mathrm{K}_{\mathrm{FLR}}=$ maximum flexion during loading response, $\mathrm{K}_{\mathrm{E}}=$ maximum extension in stance phase, $\mathrm{K}_{\mathrm{FS}}=$ maximum flexion in swing phase, $\mathrm{K}_{\mathrm{IR}}=$ maximum internal rotation in stance phase, $\mathrm{K}_{\mathrm{ER}}=$ maximum external rotation in swing phase. ${ }^{*} p<.05$.

Table 4

Symmetry indexes for knee joint angles for bionic knee joints (SI Rheo), hydraulic knee joints (SI Hydraulic) and the control group (SI Control)

\begin{tabular}{lccccc}
\hline Variable & SI Rheo (\%) & SI Hydraulic (\%) & SI Control (\%) & ES/sig. Rheo & ES/sig. Hydraulic \\
\hline $\mathrm{K}_{\mathrm{FHC}}$ & $5.76 \pm 4.52$ & $2.19 \pm 2.05$ & $1.11 \pm 0.86$ & 1.43 & 0.70 \\
$\mathrm{~K}_{\mathrm{FLR}}$ & $77.56 \pm 11.43$ & $79.22 \pm 10.62$ & $3.56 \pm 2.12$ & $9.00 / *$ & $9.88 /^{*}$ \\
$\mathrm{~K}_{\mathrm{E}}$ & $8.46 \pm 4.12$ & $48.48 \pm 12.56$ & $2.87 \pm 1.52$ & 1.80 & $4.28 / *$ \\
$\mathrm{~K}_{\mathrm{FS}}$ & $15.91 \pm 9.44$ & $0.53 \pm 1.12$ & $1.28 \pm 0.56$ & 2.19 & 0.85 \\
$\mathrm{~K}_{\mathrm{IR}}$ & $15.21 \pm 4.22$ & $20.18 \pm 4.12$ & $2.26 \pm 1.06$ & $4.21 /^{*}$ & $5.96 / *$ \\
$\mathrm{~K}_{\mathrm{ER}}$ & $3.12 \pm 3.52$ & $16.72 \pm 5.21$ & $2.15 \pm 0.95$ & 0.38 & $3.89 / *$ \\
\hline
\end{tabular}

Note. $\quad$ ES Rheo = difference between the bionic joint group and the control group; ES Hydraulic = difference between the hydraulic joint group and the control group. $\mathrm{K}_{\mathrm{FHC}}=$ flexion at heel contact; $\mathrm{K}_{\mathrm{FLR}}=$ maximum flexion during loading response; $\mathrm{K}_{\mathrm{E}}=$ maximum extension in stance phase; $\mathrm{K}_{\mathrm{FS}}=$ maximum flexion in swing phase; $\mathrm{K}_{\mathrm{IR}}=$ maximum internal rotation in stance phase; $\mathrm{K}_{\mathrm{ER}}=$ maximum external rotation in swing phase. $\quad * p<.05$. 
$(\mathrm{ES}=2.55 ; p=.04)$ from the patients using bionic knee joints. For the other parameters, the bionic joint patients show no significant difference from the control group. In all parameters, with exception minimum pelvic obliquity in the frontal plane, statistically and practically significant difference between bionic and hydraulic group was found (Table 5).

\section{Discussion}

The aim of this study was to compare the kinematics of the pelvis, hip joint and knee joint and gait symmetry in persons with bionic knee joints and persons with hydraulic knee joints and to determine differences between the control group of non-amputees. The functionality of an affected lower limb should substitute for the function of an intact limb. Gait symmetry in patients with one affected limb is important in order to prevent excessive loading of the intact limb (Nolan et al., 2003). For the hip joint, the angles recorded in patients with bionic knee joints show greater symmetry in all monitored parameters in comparison with hydraulic knee. Greater gait symmetry when using bionic knee joints is important due to its impact on energy expenditure. Energy expenditure is significantly lower when using bionic knee joints than when using hydraulic knee joints (Johansson et al., 2005). A high level of knee joint asymmetry occurs in both groups of amputees during flexion in the stance phase. This asymmetry is caused by the very low flexion of the affected limb knee joint in the stance phase. This low flexion in the stance phase is probably caused by patients' attempts to retain stability in the support phase in the affected limb. This conclusion is in accordance with other studies which described inadequate flexion in patients with various types of prosthetic knee joints (Johansson et al., 2005; Kaufman et al., 2012; Segal et al., 2006).

In both groups of amputees there is higher maximum flexion of the hip joint during the swing phase for the intact limb in comparison with control group. This flexion is significantly higher in hydraulic joint patients than in the control group and in the bionic joint patients. This greater flexion is connected with the longer duration of the stance phase on the intact limb compared with the affected limb (Petersen, Comins, \& Alkjær, 2010; Uchytil, Jandacka, Zahradnik, Farana, \& Janura, 2014). The intact limb is a more stable source of support for patients than the affected limb. The step length, which is greater when starting from the intact limb, corresponds with the greater extent of movement in the hip joint.

Patients with hydraulic joints show significantly lower flexion in the hip joint than both the control group and the bionic joint group during heel contact with the intact limb, and they show significantly higher flexion during heel contact with the affected limb. These differences were also found in studies by Kaufman et al. (2012) and Johansson et al. (2005). This difference causes a high degree of asymmetry between the two sides in terms of the hip joint angle during heel contact. One reason may be the greater difficulty of controlling the hydraulic joint, leading in turn to worse coordination between the thigh and shank.

Pelvic stability is generally reduced in transfemoral amputees (Goujon-Pillet, Sapin, Fodé, \& Lavaste, 2008). In our study, the patients with hydraulic knee joints showed significant differences in pelvic movement compared with the control group and bionic knee group. The extent of pelvic movement in frontal and transverse plane is greater in hydraulic joint patients than in the control group and bionic joint patients. Greater extents of pelvic movement may cause back pain in the long term (Sagawa et al., 2011). Lower back pain is frequently a secondary complication in singlelimb amputees (Gailey, Allen, Castles, Kucharik, \& Roeder, 2008).

The advantages of bionic joints are mainly connected with the movement of the hip and pelvis. However, it will be necessary for further studies to focus on

Table 5

Comparison of pelvic movement parameters for patients with bionic knee joints (Rheo), patients with hydraulic knee joints (Hydraulic) and the control group (Control)

\begin{tabular}{lcccccc}
\hline Variable & Rheo & Hydraulic & Control & ES/sig. Rheo & ES/sig. Hydraulic & ES/sig. R - H \\
\hline $\mathrm{P}_{\mathrm{T}}\left({ }^{\circ}\right)$ & $-5.88 \pm 3.23$ & $-10.75 \pm 2.67$ & $-3.82 \pm 2.21$ & 0.93 & $3.14 / *$ & $1.66 / *$ \\
$\mathrm{P}_{\text {OMIN }}\left({ }^{\circ}\right)$ & $-3.48 \pm 1.35$ & $-5.73 \pm 5.03$ & $-2.14 \pm 1.24$ & 1.08 & $2.9 / *$ & 0.58 \\
$\mathrm{P}_{\text {OMAX }}\left({ }^{\circ}\right)$ & $6.70 \pm 1.47$ & $15.24 \pm 8.97$ & $2.67 \pm 1.58$ & 2.55 & $7.96 / *$ & $1.26 / *$ \\
$\mathrm{P}_{\mathrm{R}}\left({ }^{\circ}\right)$ & $6.13 \pm 1.17$ & $13.21 \pm 2.78$ & $5.02 \pm 2.12$ & 0.52 & $3.86 / *$ & $3.20 / *$ \\
\hline
\end{tabular}

Note. ES Rheo = difference between the bionic joint group and the control group; ES Hydraulic = difference between the hydraulic joint group and the control group. ES R - H = difference between the bionic joint group and the hydraulic join group. $\mathrm{P}_{\mathrm{T}}=$ minimum pelvic tilt in sagital plane; $\mathrm{P}_{\text {OMIN }}=$ minimum pelvic obliquity in frontal plane; $\mathrm{P}_{\text {OMAX }}=$ maximum pelvic obliquity in frontal plane; $\mathrm{P}_{\mathrm{R}}=$ maximum rotation in transverse plane. ${ }^{*} p<.05$. 
the interaction among individual segments in order to gain a better understanding of gait strategies applied with different types of prosthetic knee joints.

\section{Conclusion}

Gait kinematics in transfemoral amputees using bionic knee joints show greater symmetry than in amputees using hydraulic joints. These differences are most prominent in the movement of the hip joint. The kinematic characteristics of gait with bionic joints are more similar to those found in individuals with no locomotion-related problems. However, regardless of the type of prosthetic joint used, amputees show significantly lower knee joint flexion during the stance phase on the affected limb. When using hydraulic knee joint there is a greater extent of pelvic movement in frontal and transverse planes than when using bionic joint, these differences are also practically significant in comparison with the control group.

\section{Acknowledgments}

This work was supported by IGS Grants 6108/2010 and $6113 / 2011$ of the University of Ostrava, research grant of Silesian region RRC/04/2009 and research grant No MSM 6198959221 of the Ministry of Education, Youth and Sport, Czech Republic, "Physical activity and inactivity of inhabitants of the Czech Republic in the context of behavioral changes".

\section{Conflict of interest}

There were no conflicts of interest.

\section{References}

Bartlett, R., Wheat, J., \& Robins, M. (2007). Is movement variability important for sports biomechanists? Sports Biomechanics, 6, 224-243.

Bellmann, M., Schmalz, T., \& Blumentritt, S. (2010). Comparative biomechanical analysis of current microprocessor-controlled prosthetic knee joints. Archives of Physical Medicine and Rehabilitation, 91, 644-652.

Benedetti, M. G., Catani, F., Leardini, A., Pignotti, E., \& Giannini, S. (1998). Data management in gait analysis for clinical applications. Clinical Biomechanics, 13, 204-215.

Cappozzo, A., Figura, F., Gazzani, F., Leo, T., \& Marchetti, M. (1982). Angular displacement in the upper body of AK amputees during level walking. Prosthetics and Orthotics International, 6, 131-138.
Dingwell, J. B., Davis, B. L., \& Frazier, D. M. (1996). Use of an instrumented treadmill for real-time gait symmetry evaluation and feedback in normal and trans-tibial amputee subjects. Prosthetics and Orthotics International, 20, 101-110.

Dormandy, J., Heeck, L., \& Vig, S. (1999). Major amputations: Clinical patterns and predictors. Seminars in Vascular Surgery, 12, 154-161.

Gailey, R., Allen, K., Castles, J., Kucharik, J., \& Roeder, M. (2008). Review of secondary physical conditions associated with lower-limb amputation and long-term prosthesis use. Journal of Rehabilitation Research and Development, 45, 15-29.

Goujon-Pillet, H., Sapin, E., Fodé, P., \& Lavaste, F. (2008). Three-dimensional motions of trunk and pelvis during transfemoral amputee gait. Archives of Physical Medicine and Rehabilitation, 89, 87-94.

Hemakumar, D., Tumilty, S., \& Smith, C. (2012). Physical activity and lower-back pain in person with traumatic transfemoral amputation: A national cross-sectional survey. Journal of Rehabilitation Research \& Development, 49, 1457-1466.

Hopkins, W. G. (2000). Measures of reliability in sports medicine and science. Sports Medicine, 30, 1-15.

Hopkins, W. G. (2014). A new view of statistics. Retrieved from http://sportsci.org/resource/stats/effectmag.html

Johansson, J. L., Sherrill, D. M., Riley, P. O., Bonato, P., \& Herr, H. (2005). A clinical comparison of variable-damping and mechanically passive prosthetic knee devices. American Journal of Physical Medicine \& Rehabilitation, 84, 563-575.

Kaufman, K. R., Frittoli, S., \& Frigo, C. A. (2012). Gait asymmetry of transfemoral amputees using mechanical and microprocessor-controled prosthetic knees. Clinical Biomechanics, 27, 460-465.

Kishner, S. (2013). Gait analysis after amputation. Retrieved from http://emedicine.medscape.com/article/ 1237638-overview\#a 1

Mâaref, K., Martinet, N., Grumillier, C., Ghannouchi, S., André, J. M., \& Paysant, J. (2010). Kinematics in the terminal swing phase of unilateral transfemoral amputees: Microprocessor-controlled versus swing-phase control prosthetic knees. Archives of Physical Medicine and Rehabilitation, 91, 919-925.

Morgenroth, D. C., Shakir, A., Orendurff, M. S., \& Czerniecki, J. M. (2009). Low-back pain in transfemoral amputees: Is there a correlation with static or dynamic leglength discrepancy? American Journal of Physical Medicine \& Rehabilitation, 88, 108-113.

Nolan, L., Wit, A., Dudziñski, K., Lees, A., Lake, M., \& Wychowañski, M. (2003). Adjustments in gait symmetry with walking speed in trans-femoral and trans-tibial amputees. Gait and Posture, 17, 142-151.

Petersen, A. O., Comins, J., \& Alkjær, T. (2010). Assessment of gait symmetry in transfemoral amputees using C-Leg compared with 3R60 prosthetic knees. Journal of Prosthetics and Orthotics, 22, 106-113.

Sagawa, Y., Turcot, K., Armand, S., Thevenon, A., Vuillerme, N., \& Watelain, E. (2011). Biomechanics and physiological parameters during gait in lower-limb amputees: A systematic review. Gait and Posture, 33, 511-526. 
Schaarschmidt, M., Lipfert, S. W., Meier-Gratz, C., Scholle, H.-C., \& Seyfarth, A. (2012). Functional gait asymmetry of unilateral transfemoral amputees. Human Movement Science, 31, 907-917.

Segal, D. A., Orendurff, M. S., Klute, G. K., McDowell, M. L., Pecoraro, J. A., Shofer, J., \& Czerniecki, J. M. (2006). Kinematic and kinetic comparison of transfemoral amputee gait using C-Leg and Mauch SNS prosthetic knees. Journal of Rehabilitation Research \& Development, 43, 857-870.

Silver-Thorn, B. M., \& Glaister, C. L. (2009). Functional stability of transfemoral amputee gait using the $3 \mathrm{R} 80$ and
Total Knee 2000 prosthetic knee units. Journal of Prosthetics and Orthotics, 21, 18-31.

Stoquart, G., Detrembleur, C., \& Lejeune, T. (2008). Effect of speed on kinematic, kinetic, electromyographic and energetic reference values during treadmill walking. Clinical Neurophysiology, 38, 105-116.

Uchytil, J., Jandacka, D., Zahradnik, D., Farana, R., \& Janura, M. (2014). Temporal-spatial parameters of gait in transfemoral amputees: Comparison of bionic and mechanically passive knee joints. Prosthetics and Orthotics International, 38, 199-204. 